\title{
Maintaining The Integrity Of Turnover Measurements When There Are Layoffs
}

Theodore Mitchell, University of Nevada, USA

James I. Schaap, University of Nevada, USA

Mary Groves, University of Nevada, USA

\begin{abstract}
Bonuses for improvements in employee retention rates should be calculated on the actual savings due to fewer terminations and reduced replacement costs. Permanent layoffs and hiring freezes distort the turnover rate and make the normal bonus calculations invalid. A new method for calculating a manager's bonus for reducing the turnover rate is illustrated. It isolates the number of terminations due to changes in the size of the workforce from the terminations due to the improved retention rate. The size of the savings in terminations due to the improved retention rate can be accurately measured in situations where hiring freezes negate normal calculations.
\end{abstract}

\section{INTRODUCTION}

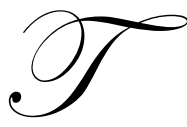

he purpose of this paper is to define turnover in a manner that allows managers to be rewarded for improving employee retention rates in times when layoffs and hiring freezes make the normal bonus calculations impossible. The mathematics in the paper illustrates how the impact of a changing turnover rate can be measured in terms of savings in the total termination cost.

There are two major costs associated with employee turnover rates. The first is the direct cost of terminating an employee's relationship with a firm and may be between $93 \%$ and $200 \%$ of an employee's salary (Johnson 1995). The cost of terminating an employee is often discussed as a separation cost (Smith and Watkins, 1976) and includes any separation pay, unemployment tax, as well as the costs of exit interviews and other administrative functions. The second cost is associated with recruiting and training a replacement for a departing employee (Branch, 1998). The focus of this paper is on the expenses associated with terminating employees and ignores the replacement costs associated with turnover rates. The focus on the termination cost is due to our emphasis on the role of permanent layoffs and hiring freezes on the total cost terminations.

It is generally accepted that firms with good morale, good management, etc. will have higher employee retention rates and lower turnover rates, and conversely, fewer terminations and lower total termination costs. The emphasis in the literature on human resource management is understanding and improving employee retention. It is generally understood that if the retention rate is $90 \%$, then the turnover rate is $10 \%$. However, there has been some confusion in the literature as to the definition of the types of employee departures to be included in the definition of turnover. Some authors, Wayne Cascio (2000), Macy and Mirvis (1976), define turnover as any departure from the organization and their definitions include all forms of separation such as voluntary, involuntary and permanent layoffs, regardless of the motivation for the separation. Other authors, Mavis and Jackson (2008), define turnover as employees who withdraw from an organization and have to be replaced. Both of these definitions are inadequate for calculating the bonus for a manager who is improving employee retention in times of layoffs and hiring freezes.

\section{DEFINING LAYOFF, TERMINATION AND TURNOVER}

In this paper, a termination is defined as any departure from the firm for any reason, voluntary or involuntary and permanent layoffs. A termination rate, $\mathrm{S}$, is the number of terminations, D, divided by the average size of the workforce, $N$, for the year (i.e., $S=D / N$ ). 
A permanent layoff is defined as an involuntary termination in which the sole reason for the employee's separation is the firm's motivation for a permanent reduction in the size of the workforce. There are no intentions of a replacement for a permanent layoff, and as such, a layoff is defined as a firing strategy in order to achieve a smaller workforce.

A termination due to a turnover is defined as any departure from the organization for any possible reason except a layoff. That is to say, any termination, which cannot be directly attributed to a layoff, is a turnover. The turnover rate, $\mathrm{R}$, is the number of turnovers, $\mathrm{T}$, divided by the average size of the workforce, $\mathrm{N}$, for the year (i.e., $\mathrm{R}=\mathrm{T} / \mathrm{N})$.

This definition of turnover is different from most because it does not require any knowledge of the firm's intention for replacement when a separation occurs. For example, turnovers that occur during a hiring freeze are not considered layoffs. A hiring freeze is designed to reduce the size of the workforce by not replacing turnovers; but it is a reduction through a hiring strategy.

Under normal conditions, the number of terminations over a given period of time will equal the turnovers. That is to say, if there are no permanent layoffs, then the number of terminations, $\mathrm{T}$, must equal the number of turnovers, $\mathrm{S}$, and the turnover rate, $\mathrm{C}$, must equal the termination rate, $\mathrm{T}$.

\section{DEFINING WORKFORCE SIZE AND CHURN}

The definition of turnover, $\mathrm{R}$, and termination, $\mathrm{S}$, rates implies the need for a clear definition of the workforce size, $\mathrm{N}$. The workforce size is defined as the number of employees inside an organizational boundary. The boundary can be the total organization or it may be an organizational division, department, profit center, or strategic business unit. The number of employees inside an organizational boundary, e.g., a sales department, is the size of the workforce and a single organization may have many workforces. Churn occurs when some workforces in an organization are hiring people while others are involved in layoffs (Mathis and Jackson, 2008). Layoffs and hiring are strategies designed to impact the size of a defined workforce. By definition, a single workforce cannot engage in layoffs, to permanently reduce its size, while simultaneously engage in hiring, to permanently increase its size. The churn of simultaneous hiring and layoffs can be an apparent paradox for an organization as a whole, but there is no churn inside the organizational boundary of the defined workforce.

Firms can adopt three different hiring strategies for any defined workforce: 1) A firm's hiring strategy may involve the deliberate growth of the workforce and recruitment is greater than separations due to turnover. 2) A firm's hiring strategy is to maintain the current size of the workforce and recruitment is limited to the replacement of all separations due to turnover. 3) A firm's hiring strategy is to reduce the size of the workforce through attrition and recruitment is less than the turnover. When a firm uses a "hiring freeze" and attrition to achieve a reduction, then the size of the reduction is limited to the size of the turnover. Turnovers that are not replaced because of the hiring freeze are not considered layoffs. Permanent layoffs are necessary in situations where the turnover rate is not large enough to achieve the needed reduction in the workforce size.

Terminations due to turnover always occur and managers who improve the employee retention rates in a workforce should be recognized and rewarded in good times as well as bad times. The basis for a manager's bonus is the reduction in the cost of terminations. However, large layoffs cause large increases in the total termination cost and hiring freezes change the denominator of the turnover rates. In turbulent times the traditional bonus calculations based on simple percentage changes are inadequate. This paper demonstrates the mathematics necessary to isolate and calculate the savings due to improved retention rates in situations where large layoffs distort the normal turnover rates. When the total costs of termination are increasing, it is very difficult to award and justify a bonus for savings that cannot be easily identified or calculated. The mathematics in this paper demonstrate that a management bonus can be paid, and justified, for reducing termination cost due to turnover in situations where the total termination cost has increased. 


\section{CALCULATING THE SAVINGS IN TERMINATION COSTS DUE TO IMPROVED RETENTION}

In the example illustrated in Table 1, there is no permanent layoff or hiring freeze and it is assumed that a manager's morale and retention program has been successful in reducing the terminations due to turnover from year 1 to year 2 by $10 \%$. In normal times there is a direct and obvious link between the improvements in the turnover rate $(-10 \%)$ and the total cost of terminations $(-10 \%)$. The basic calculation for number of turnovers, $\mathrm{T}$, in each year is

$\mathrm{T}=\mathrm{R} \times \mathrm{N}$

Equation 1

Where

$\mathrm{T}=$ the number of employee terminations in a period

$\mathrm{R}=\mathrm{T} / \mathrm{N}=$ the turnover rate

$\mathrm{N}=$ the average number of employees in the population for the period

Table 1

Calculating Savings Due to Improved Turnover in Normal Times

\begin{tabular}{|c|c|c|c|c|}
\hline 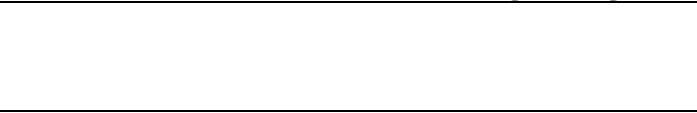 & Year 1 & Year 2 & Change & $\begin{array}{c}\text { Percentage } \\
\text { Change from } \\
\text { year } 1 \\
\end{array}$ \\
\hline Size of workforce, $\mathbf{N}$ & 1000 & 1000 & 0 & 0 \\
\hline Turnover Rate, $\mathbf{R}$ & $25 \%$ & $22.5 \%$ & $-2.5 \%$ & $-10 \%$ \\
\hline Total Number of Terminations due to Turnover, $T$ & 250 & 225 & -25 & $-10 \%$ \\
\hline Cost per Termination, $\mathbf{E}$ & $\$ 1,000$ & $\$ 1,000$ & 0 & 0 \\
\hline Total Termination Expense, B & $\$ 250,000$ & $\$ 225,000$ & $-\$ 25,000$ & $-10 \%$ \\
\hline
\end{tabular}

The $\$ 25,000$ in savings from year 1 to year 2 is entirely due to the manager's success in improving the retention rate from $75 \%$ to $77.5 \%$ and the $10 \%$ reduction in termination costs.

\section{THE IMPACT OF A HIRING FREEZE CHANGING WORKFORCE SIZE}

Common usage in normal times has resulted in managers concentrating on the magnitude of their turnover rates, $\mathrm{R}$, as a prime performance metric. In normal times, there is little danger in stressing the turnover rate as the central metric of performance and control because there is little change in the denominator of the turnover rate. That is to say, the size of the workforce is assumed to be stable.

The literature does not discuss how changes in the overall size of the firm's workforce can impact the turnover rate. In the first example shown in Table 1, there is no change in the size of the workforce, N. However, in the second example (Table 2), there is a deliberate hiring strategy to reduce the size of the workforce from 1,000 employees in period 1 to 800 employees in period 2. The strategy of hiring freeze reduces the size of the workforce through the attrition of the turnover rate. That is to say, there is no single-shot layoff of 200 employees and the workforce is reduced to the desired level by not replacing terminations due to turnover. The turnover rate of $25 \%$ and the $\$ 1,000$ cost per termination remain constant.

Table 2

Calculating Savings When Downsizing Through Attrition

\begin{tabular}{|l|c|c|c|c|}
\hline & Year 1 & Year 2 & Change & $\begin{array}{c}\text { Percentage } \\
\text { Change }\end{array}$ \\
\hline Size of workforce, $\mathbf{N}$ & 1000 & 800 & -200 & $-20 \%$ \\
\hline Turnover Rate, R & $25 \%$ & $25 \%$ & $-0 \%$ & 0 \\
\hline Total Number of Terminations, $\mathbf{T}$ & 250 & 200 & -50 & $-20 \%$ \\
\hline Cost per Termination, E & $\$ 1,000$ & $\$ 1,000$ & 0 & 0 \\
\hline Total Termination Expense, B & $\$ 250,000$ & $\$ 200,000$ & $-\$ 50,000$ & $-20 \%$ \\
\hline
\end{tabular}


Having a smaller workforce with the same $25 \%$ turnover rate reduces the total number of turnovers by $20 \%$ and the termination cost by $\$ 50,000$ from year 1 to year 2 . The $\$ 50,000$ in savings is entirely due to the hiring freeze that reduced the total number of termination by 50 and the total workforce by 200 people. There is no justification for a managerial bonus because the turnover rate has not changed and the savings occur because smaller firms have fewer terminations than large firms, certis paribus.

The first and second examples illustrate two potential sources for reducing the number of terminations. The first source is the reduction in turnover rate due to improved employee retention. The second source is the reduction in the size of the workforce. In normal times, fluctuations in the size of the workforce are small and are easily ignored in calculating percentages. However, in turbulent times when hiring freezes are used to achieve smaller workforces, the impact on total terminations is significant and percentages become distorted.

\section{CALCULATING A BONUS FOR IMPROVED RETENTION RATES AND A HIRING FREEZE}

The situation of a firm experiencing lower total termination costs through both a downsizing by attrition and a lower turnover rate can be exemplified by combining the examples in Table 1 and 2 into Table 3.

Table 3

Percentage Changes Due to Improved Retention and the Hiring Freeze

\begin{tabular}{|l|c|c|c|c|}
\hline & Year 1 & Year 2 & Change & $\begin{array}{c}\text { \% change from } \\
\text { year 1 }\end{array}$ \\
\hline Size of workforce, $\mathbf{N}$ & 1000 & 800 & -200 & $20 \%$ \\
\hline Turnover Rate, R & $25 \%$ & $22.5 \%$ & $-2.5 \%$ & $10 \%$ \\
\hline Total Number of Terminations, $\mathbf{T}$ & 250 & 180 & -70 & $28 \%$ \\
\hline Cost per Termination, E & $\$ 1,000$ & $\$ 1,000$ & 0 & \\
\hline Total Termination Expense, B & $\$ 250,000$ & $\$ 180,000$ & $-\$ 70,000$ & $-\$ 70,000$ \\
\hline
\end{tabular}

Together, the impacts of two changes reduce the total termination expense by $\$ 70,000$. The numbers in Table 3 highlight the difficulty of isolating the savings when two changes occur simultaneously. To award an appropriate bonus to the manager, it is necessary to identify the share of the $\$ 70,000$ saving that is due directly to the improved retention rate (i.e., lower turnover rate). There is no obvious way to use the simple percentage changes to calculate the actual dollar impact of each change on the $\$ 70,000$ in total savings. When there is one change at a time as in Table 1 and Table 2, then savings due to the manager are $\$ 25,000$ and savings due to the hiring freeze are $\$ 50,000$. Together as independent changes they sum to $\$ 75,000$, but the actual saving when both are applied together is only $\$ 70,000$. There is an interaction effect that must be isolated and the savings due to the downsizing of the firm's workforce need to be isolated from the savings due to the improved retention rate.

\section{THE MATHEMATICS FOR ISOLATING AND CALCULATING THE TWO SAVINGS}

The procedure proposed in this paper for identifying the amount of the total saving that is due to improved retention and the amount that is due to workforce reduction is to expand the simple turnover rate in Equation 1.

The total number of terminations in year 2 is the product of turnover rate, $R_{2}$, and workforce size, $N_{2}$, in year 2. That is to say, the difference from year 1 to year 2 is

$\mathrm{T}_{2}-\mathrm{T}_{1}=\left(\mathrm{R}_{2} \times \mathrm{N}_{2}\right)-\left(\mathrm{R}_{1} \times \mathrm{N}_{1}\right)$

Equation 2

Equation 2 is expanded to show the change in total terminations, $\Delta \mathrm{T}$, from year to year as the sum of the various improvements. That is to say, the net change in total terminations is due to improved turnover, $\Delta \mathrm{R}$, plus the reduction in workforce size, $\Delta \mathrm{N}$, plus any joint or interactive impact, $\mathrm{J}$, due to a simultaneous change of the variables. 
$\Delta \mathrm{T}=\Delta \mathrm{N}+\Delta \mathrm{R}+\mathrm{J}$

And

$\mathrm{T}_{2}-\mathrm{T}_{1}=\left(\mathrm{R}_{\min }\right)\left(\mathrm{N}_{2}-\mathrm{N}_{1}\right)+\left(\mathrm{N}_{\min }\right)\left(\mathrm{R}_{2}-\mathrm{R}_{1}\right) \times \mathrm{J}$

Equation 3

\begin{tabular}{|l|l|}
\hline where & \\
\hline$\Delta \mathrm{T}=\mathrm{T} 2-\mathrm{T} 1$ & $=$ The change in the number of terminations from year 1 to year 2 \\
\hline$\Delta \mathrm{N}=(\mathrm{Rmin})\left(\mathrm{N}_{2}-\mathrm{N}_{1}\right)$ & $=$ The number of terminations caused by the change in the workforce size \\
\hline$\Delta \mathrm{R}=\left(\mathrm{N}_{\min }\right)\left(\mathrm{R}_{2}-\mathrm{R}_{1}\right)$ & $=$ The number of terminations caused by the change in the turnover rate \\
\hline $\mathrm{J}$ & $=$ The number of terminations due to the joint or interactive effect of simultaneous changes \\
\hline
\end{tabular}

\section{CALCULATING INDEPENDENT SAVINGS DUE TO THE INDIVIDUAL CHANGES}

It is the savings due to the joint or interaction effect of changing turnover rate and workforce size simultaneously that negates an intuitive approach to calculating the saving due to each individual change.

The reduction in termination expense that is solely due to the change in size of the workforce:

$\Delta \$ N=E\left(R_{\min }\right)\left(N_{2}-N_{1}\right)=\$ 1,000 \times 0.225(800-100)=1,000 \times-0.225 \times 200=-\$ 45.000$

The reduction in termination expense that is solely due to the change in turnover rate:

$\Delta \$ R=E\left(N_{\min }\right)\left(R_{2}-R_{1}\right)=1,000 \times 800(25 \%-22.5 \%)=\$ 1,000 \times 800 x-2.5 \%=-\$ 20,000$

Sum of the savings that can be directly and independently attributed to the changes in workforce size, $\Delta \$ N$ $=\$ 45,000$, and turnover rate, $\Delta \$ R=\$ 20,000$, is $\$ 65,000$.

Savings due to the joint or interactive effect of the two changes occurring simultaneously:

$\mathrm{J}=\Delta \$ \mathrm{~T}-\Delta \$ \mathrm{~N}-\Delta \$ \mathrm{R}=\$ 70,000-\$ 45,000-\$ 20,000=\$ 5,000$

The ultimate goal is to award the manager a bonus based on the $\$ 20,000$ in savings that is the direct result of his program to improve retention rates plus a fair share of the $\$ 5,000$ in joint savings. The goal is achieved by allocating the total net savings of $\$ 70,000$ in the same proportion as the contribution to the sum of the independent savings, $\$ 65,000$. The change in workforce size contributes $(45,000 / 65,000=) 69 \%$ of the total independent savings and $\$ 48,462$ of the total $\$ 70,000$ in net savings.

The change in turnover rate contributes $(20,000 / 65,000=) 31 \%$ of the total independent savings and $\$ 21,538$ of the total $\$ 70,000$ in net savings. The manager's share of the $\$ 70,000$ savings for improved retention rates is $\$ 21.538$.

Table 4

Calculating the Savings Due To Improved Retention and the Layoffs by Attrition

\begin{tabular}{|l|c|c|c|c|}
\hline & Year 1 & Year 2 & Change & $\begin{array}{c}\text { Savings Due to } \\
\text { each of the two } \\
\text { changes }\end{array}$ \\
\hline Size of workforce, $\mathbf{N}$ & & & -200 & $\$ 48,462$ \\
\hline Turnover Rate, R & 1000 & 800 & $-2.5 \%$ & $\$ 20,538$ \\
\hline Total Number of Terminations, $\mathbf{T}$ & $25 \%$ & $22.5 \%$ & -70 & \\
\hline Cost per Termination, E & 250 & 180 & 0 & \\
\hline Total Termination Expense, B & $\$ 1,000$ & $\$ 1,000$ & $-\$ 70,000$ & $\$ 70,000$ \\
\hline
\end{tabular}




\section{AN ILLUSTRATION OF THE THREE IMPACTS}

The problem of isolating and calculating the size of the three separate impacts on total terminations calculated by Equation 3 are illustrated in Figure 1. Area 4 represents the total 180 terminations in year 2 and is equal to the product of the $22.5 \%$ turnover rate and the 800 employees. Area 1 represents the impact on the change in terminations that is strictly due to the change in the turnover rate. Area 1 represents 20 terminations and is calculated by multiplying the change in the termination rate, $2.5 \%$, times the minimum number of employees, 800 , in the past two years. Area 2 represents the impact on the change in terminations that is strictly due to the change in the size of the workforce.

The impact on the change in terminations, when only the turnover rate is changed is 25 terminations and is the sum of the turnovers in Area 1 and Area 3. It is calculated as the percentage change in turnover (-2.5\%) times the size of the workforce (1,000 employees), which remained unchanged in the first example.

The impact on the change in terminations, when only the size of the workforce is changed (refer to Table 2 ), is 50 terminations and is the sum of the turnovers in Area 2 and Area 3. It is calculated as the size of the workforce change (200 employees), times the turnover rate (25\%), that remained constant in the second example.

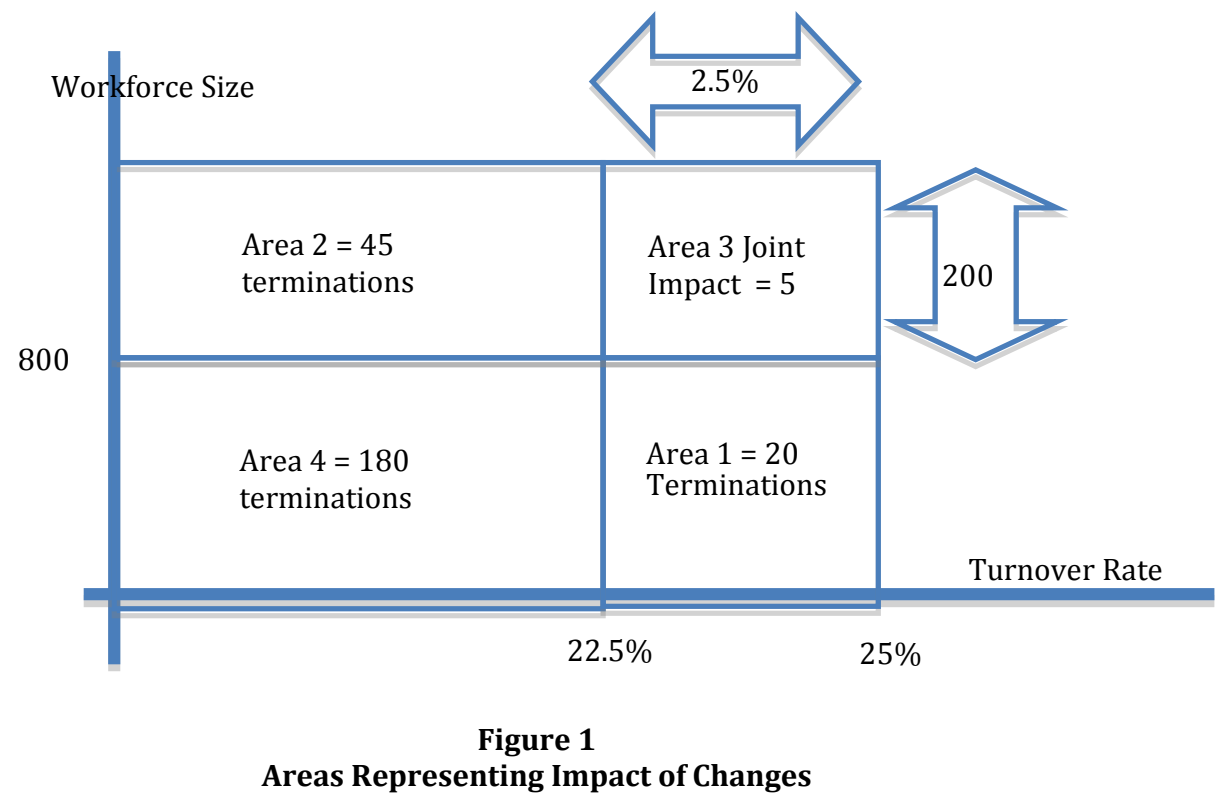

\section{CONCLUSION AND DIRECTIONS FOR FURTHER ANALYSIS}

The isolation of savings due to changes in workforce size from changes in the retention rate requires a modification to the traditional definition of turnover. We introduced the definition of a termination that includes all reasons for an employee separation. Permanent layoffs, which in practice are easily recognized, are defined to be terminations that are not to be included in the definition of turnover. A turnover is a separation for any motivation except a permanent layoff designed to reduce the size of the workforce.

Cascio (2000, p.14) suggests that many different types of turnover measures might be defined and that any proposed formula must pass two tests: 1) it must allow for year-to-year performance changes, and 2) permit company-to-company comparisons. Equation 3 is constructed on the changes in turnover from year to year. We believe that the definitions of termination, layoff and turnover used in this paper allow Equation 3 to be applied to different workforces with comparable results. In normal times there are no permanent layoffs and the classic definition of the turnover rate (Cascio, 2000) is equal to the turnover rate defined in the paper. The decomposition of 
the total terminations into those that are layoffs and those that are turnovers does not change the conventional calculations of retention rates except in situations where there are single-shot layoffs.

Based on the examples presented in this paper, we conclude that equation 3 is a general solution to the bonus calculation because it is applicable to situation with or without hiring freezes. That is to say, Equation 3 deals with situations where there is a change in a single variable or changes in multiple variables. It can deal with apparent improvements in turnover and retention that are actually due to changes in workforce size to growth.

We have found that equation 3 can be made applicable to situations where there are a series of successive layoffs because it measures the changes to the layoff rate from period to period. It can also be expanded to deal with the savings to overall termination cost due to the changes in the cost per termination from period to period.

Equation 3 allows for the calculation of a manager's bonus for an improved retention rate in situations where layoffs and hiring freezes can distort normal percentage calculations of savings in the number of terminations. However, Equation 3 is only the part of the bonus calculations dealing with savings in termination costs. The complete calculation requires an additional analysis of the savings due to reductions in the costs of recruiting, hiring and training that should be explored in future papers.

\section{REFERENCES}

1. Branch, S. (1998, November 9). You hired 'em, But can you keep 'em? Fortune p.247-250.

2. Cascio, W. F. (2000). Costing Human Resources, $4^{\text {th }}$ edition, Thompson South-Western, 12-16.

3. Johnston, A.A. (1995). The business case for work-family programs. Journal of Accountancy, 180(2) 5357.

4. Macy B.A. and Mirvis, P.H. (1976). Measuring the quality of worklife and organizational effectiveness in behavioral-economic terms. Administrative Quarterly 21, 212-226.

5. Mathis, R. L., and Jackson, J. H. Jackson (2008), Human Resource Management, Thompson SouthWestern $12^{\text {th }}$ edition, 85-88.

6. Smith, H.L. and Watkins, W. E. (1978), Managing manpower turnover costs. Personnel Administrator, 23(4), 46-50 
NOTES 